\title{
Reported Name of Procedure
}

National Cancer Institute

\section{Source}

National Cancer Institute. Reported Name of Procedure. NCI Thesaurus. Code C117511.

The literal identifier of the procedure. 